Article

\title{
Synthesis of an Aluminum Oxide-Based Functional Device Engineered by Corrosion/Oxidation Process
}

\author{
Roberto Baca-Arroyo \\ Department of Electronics, School of Mechanical and Electrical Engineering, National Polytechnic Institute, \\ 07738 Mexico City, Mexico; rbaca02006@yahoo.com.mx; Tel.: +52-01-5729-6000
}

Received: 21 July 2020; Accepted: 19 August 2020; Published: 21 August 2020

\begin{abstract}
A disordered aluminum oxide grown on recycled aluminum sheets was synthesized by a corrosion/oxidation process. First, aluminum sheets recovered from unusable beverage cans were mechanically polished and dried in air atmosphere. Second, corrosion and oxidation into the aqueous solutions were the synthesis stages to produce aluminum oxide. Phase formation and electrical conduction of aluminum-oxide layers were validated by $\mathrm{X}$-ray diffraction analysis and current-voltage plots at room temperature. An aluminum oxide-based structure operating under unusual principles at an extended lifetime resulted when an aluminum-oxide layer was inserted between two aluminum electrodes. This was attributed to an unusual electrical conduction. Some suggested models from the circuit theoretic properties are discussed here for potential usefulness for the aluminum oxide synthesized, as an environmental-friendly material that can be further useful into a sustainable scenario.
\end{abstract}

Keywords: waste management; recycled aluminum sheets; disordered aluminum oxide; green synthesis; sustainable functional device

\section{Introduction}

In the synthesis of metal oxides by corrosion/oxidation processes, many metals such as steel, nickel, titanium, zirconium alloys, silver, and aluminum-based alloys are well known as oxide-passivated metals, with titanium being an essential corrosion-resistant metal that may be used in high-strength applications [1,2]. Titanium is used in aerospace applications, medical implants, marine hardware, and high-purity titanium for use in electronics [3]. However, to enhance strength in titanium, titanium composites must be produced at high temperatures $\left(\sim 1000^{\circ} \mathrm{C}\right)$, which could limit their use [1]. Titanium may be replaced for applications that require corrosion gradually, depending on the environmental conditions; therefore, due to their non-toxicity and classification as a non-carcinogen [4], aluminum is the most widely used non-ferrous metal because of its non-ignition, mechanical strength, and it being the most cost-effective material to recycle.

Aluminum is the third most abundant element after oxygen and silicon and is the most abundant metal in the earth. This metal is chemically reactive, highly conductive, and non-magnetic [5]. To produce aluminum, it must be converted in aluminum oxide by the Bayer process from bauxite, the main ore of aluminum, where small crystals of aluminum hydroxide are collected to serve as seeding agents where granular particles may be converted by heating. Other manner to produce aluminum is when the alumina $\left(\mathrm{Al}_{2} \mathrm{O}_{3}\right)$, found in nature as the corundum mineral, is converted to metal by Hall-Heroult process. Both process types are highly energy-consuming. The aluminum has major uses in transportation, building and construction, machinery and equipment, packaging, as well as for electricity-related uses [3,6].

Nowadays, several challenges in aluminum production must be taken into account. The major challenge is the greenhouse gas emissions. These gases result from electrical consumption from the 
perfluorocarbons and by-products (sulfur dioxide) during processing into the smelters where released sulfur dioxide is one of the primary precursors of acid rain, and where high concentrations of toxic ions are a primary factor that disturbs root growth and its function in acidic soils [7]. Because only $5 \%$ of energy is required for recycling aluminum in comparison with that used to produce aluminum from ore [3], today recycling of beverage cans may be a crucial task where they can be effortlessly recovered to be useful as sustainable functional device [8]. However, to manufacture aluminum-based functional devices, it must be gradually oxidized as a function of its ionizing activity where initially a free aluminum atom has a radii of $1.43 \AA$, but when it is oxidized their three outermost electrons participate in the chemical compounds, which are removed, then the radii of aluminum shrinks to $0.53 \AA$ to be a six-coordinated atom [9]. Further, owing to its low heat retention, relatively high thermal conductivity $\left(30 \mathrm{Wm}^{-1} \mathrm{~K}^{-1}\right)$, and large band gap $(\sim 4.2 \mathrm{eV})$, the extended use of aluminum oxide in electronics is currently used in electrically insulated substrates for the integrated circuits, as a tunnel barrier for the fabrication of nanoscale transistors, and as dielectric in insulating barriers of capacitors [10].

The work presents the synthesis of aluminum oxide assisted by the corrosion/oxidation process. Experimental procedure for synthesis of aluminum oxide will be detailed in Section 2. Electrical conduction in aluminum oxide-based structures will be covered in Section 3. Theoretic prototypes which show that electrical conduction in disordered aluminum oxide might play an important role for the optimized signal processing in electronics. This will be presented in Section 4. Finally, conclusion about this research is presented in Section 5 .

\section{Synthesis Process for Aluminum Oxide}

Aluminum sheets of alloy 3004-H19 (Al-Mg-Mn series) recovered from useless beverage cans of an average thickness of $0.2 \mathrm{~mm}$ have been used here to synthesis of aluminum oxide. Before, aluminum sheets were cut in foils of cross-section area $2 \mathrm{~cm} \times 2 \mathrm{~cm}$. Because the sheets are internally coated with a highly electronegative thin-passivation oxide layer of $4 \mathrm{~nm}$ of thickness and electrode potential of $-1.66 \mathrm{~V}$ including epoxy resin to avoid chemical reactions [5], and also externally coated by printed shells, these must be removed on both sides of such these aluminum foils with mechanical polishing using silicon carbide $(\mathrm{SiC})$ abrasive of fine particle size to achieve a controllable chemical attack on it. Next, cleaning process was realized with a home-used organic solvent known as thinner and successively dried in air atmosphere. In the synthesis of aluminum oxide, the following three stages are involved: (1) Chemical attack into a solution in concentration at $40 \%$ for etching PCBs well known as ferric chloride $\left(\mathrm{FeCl}_{3}\right)$. (2) Removing excess of solution from the attacked surface. (3) Immersing the attacked foils inside a sterilizing solution well employed in home wound treatment where concentration of hydrogen peroxide $\left(\mathrm{H}_{2} \mathrm{O}_{2}\right)$ is $18 \mathrm{~g} / \mathrm{L}$ suitable to ensure an oxygen source.

Before, the $\mathrm{FeCl}_{3}$ solution must be activated with water to be used as electrolyte. Thus, $2.5 \mathrm{~mL}$ of $\mathrm{FeCl}_{3}$ is mixed with $2.5 \mathrm{~mL}$ of water to get 1:1 ratio. A corrosion process occurs in the aluminum foils when a chemical attack is done during $30 \mathrm{sec}$ by immersion. In this first stage, the reaction mechanism for corrosion can be written as

$$
\mathrm{FeCl}_{3}(\mathrm{aq})+\mathrm{Al}(\mathrm{s}) \rightarrow \mathrm{AlCl}(\mathrm{s})+\mathrm{FeCl}_{2}(\mathrm{aq})
$$

The species was dissolved in the solution activated with water are $\mathrm{Fe}^{+}(\mathrm{OH})^{-}$and $\mathrm{H}^{+} \mathrm{Cl}^{-}$, which indicated that the presence of $\mathrm{H}^{+}$acts as reducing agent on the aluminum surface $[5,11]$. Subsequently, the chemical attack resulted in a disordered aluminum layer. Once the foils were immersed in the previous stage, some residues of $\mathrm{FeCl}_{2}$ remain added.

In the third stage, chemically attacked foils were immersed into $\mathrm{H}_{2} \mathrm{O}_{2}$ in aqueous solution at different immersion times as indicated in Table 1. In accordance with the following reaction mechanism, a disordered aluminum-oxide that grew on the recycled aluminum sheets took place as

$$
\mathrm{AlCl}(\mathrm{s})+\mathrm{FeCl}_{2}(\mathrm{aq})+\mathrm{H}_{2} \mathrm{O}_{2}(\mathrm{aq}) \rightarrow \mathrm{Al}^{+} \mathrm{O}_{2}(\text { oxide })+\mathrm{Fe}^{+} \mathrm{Cl}^{-}+2 \mathrm{H}^{+} \mathrm{Cl}^{-}
$$


Table 1. Synthesis conditions for oxidation and lattice parameters of the produced samples.

\begin{tabular}{ccccc}
\hline Sample & $\begin{array}{c}\text { Immersion Time } \\
\text { (sec) }\end{array}$ & $\begin{array}{c}\mathbf{2 \theta} \\
\mathbf{( 2 0 2 )}\end{array}$ & $\epsilon_{\mathbf{2 \theta}}$ & $\begin{array}{c}\mathbf{t} \\
\mathbf{( n m )}\end{array}$ \\
\hline AS-1 & 20 & $46.19^{\circ}$ & -0.000432 & 515.38 \\
AS-2 & 45 & $46.25^{\circ}$ & 0.000864 & 193.78 \\
AS-3 & 70 & $46.45^{\circ}$ & 0.00516 & 32.51 \\
\hline
\end{tabular}

In the third stage, the presence of two $\mathrm{H}^{+}$ions acted as reducing agents on the aluminum surface [11]. The ionic species dissolved, such as $\mathrm{Fe}^{+} \mathrm{Cl}^{-}$and $\mathrm{H}^{+} \mathrm{Cl}^{-}$, will determine the oxidation degree, where the $\mathrm{O}^{-}$ions transferred toward the surface reacted with $\mathrm{Al}^{+3}$ ions to produce aluminum oxide of appearance opaque gray.

The X-ray diffraction with XPERT-PRO diffractometer system of $\mathrm{CuK}_{\alpha}$ radiation $(\lambda=0.1541$ $\mathrm{nm}$ ) was employed to evaluate the formation of aluminum oxide. For this analysis, $X$-ray diffraction patterns were analyzed using the PANalytical evaluation software in the $2 \theta$ scanning range from $20^{\circ}$ to $90^{\circ}$. Figure 1 shows the diffraction peaks for three samples of aluminum oxide labeled as AS-1, AS-2, and AS-3. As a reference, the diffraction pattern for an aluminum sheet recuperated from unusable beverage cans is shown. The samples resulted to be polycrystalline with rhombohedra (corundum) lattice. Several peaks appear which correspond to crystallographic planes for the preferred $\alpha-\mathrm{Al}_{2} \mathrm{O}_{3}$ phase. Displacement in the $\mathrm{X}$-ray diffraction patterns between peaks position of each aluminum-oxide layer and peaks position of recycled aluminum sheet were observed, ensuring the presence of elastic strain during the stages involved in the synthesis stages induced by disordered array of aluminum and oxygen ions into the aluminum-oxide lattice.

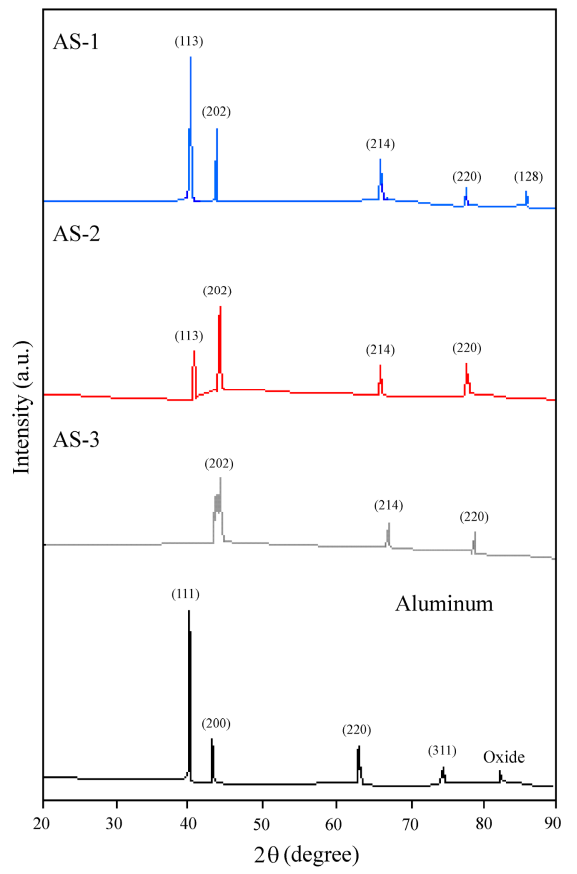

Figure 1. X-ray diffraction patterns of three different samples, where the pattern of aluminum is included as reference to identify how the formation of each layer of aluminum-oxide was made.

Because of the existence of elastic strain in aluminum-oxide layers, the minimum thickness for carrier conduction in the absence of scattering events must be estimated by Scherrer relation $t \sim \lambda\left[\epsilon_{2 \theta}\right.$ $\cos \theta]^{-1}$, where the average elastic strain is $\epsilon_{2 \theta}=\left(d-d_{0}\right) d^{-1}$ with $d$ as the measure plane spacing and $\mathrm{d}_{0}$ as the unstrained plane spacing [12]. In Table 1, the estimated thickness for the samples is given where their significant plane is corresponding to the area under (202) reflection peak. 
The importance of obtaining the $t$ parameter is that it lets us know how much disordered oxide occurs when the aluminum oxide grows as a function of the aluminum-surface corrosion, which will result in the aluminum atoms being visualized as layers of hexagonal close-packed oxygen atoms with small aluminum atoms in two-thirds of the octahedral coordinated holes between the oxygen atoms [13], such that oxide behaves like to a defective oxide [14-16].

It is well know that aluminum cans are alloyed to improve their physical properties using non-heat-treatable forming process, for example, mechanical hardness and corrosion resistance in $\mathrm{Al}-\mathrm{Mg}-\mathrm{Mn}$ series when these are exposed to temperature changes. The alloying metals in aluminum cans typically are $5 \%$ magnesium, $1 \%$ manganese, $0.1 \%$ chromium, as well as iron and silicon in a few percent per weight [17]. Therefore, the X-ray diffraction analysis in Figure 1 confirms that the recycled aluminum sheets are corresponding with above $90 \%$ aluminum in accordance with the peak-assignment cards, which guarantee that the structure properties for the aluminum oxide previously synthesized do not depend on the alloying metals.

\section{Electrical Conduction in Aluminum Oxide-Based Structures}

This section discusses how is the electrical conduction in aluminum-oxide layers (samples) synthesized with emphasis on knowledge of their conduction properties. Before, these samples must be cut with an area of $0.5 \mathrm{~cm} \times 0.5 \mathrm{~cm}$ and inserted between two electrodes, as shown in the aluminum oxide-based structure of Figure 2a. Electrical conduction measurements are performed and evaluated by current-voltage plots at room temperature using a digital storage oscilloscope (Tektronix, TDS1012C). A function generator (Matrix, MFG-8250A) is used to produce the sine wave at low frequency $(\mathrm{f}=100 \mathrm{~Hz}$ ) with magnitude scanned from $-10 \mathrm{~V}$ to $10 \mathrm{~V}$, which is connected between the bottom and upper aluminum electrodes of an area $1 \mathrm{~cm}^{2}$, to ensure the bipolar-biased condition. These large-area electrodes acting as contacts were mechanically fixed to avoid surface deteriorating.

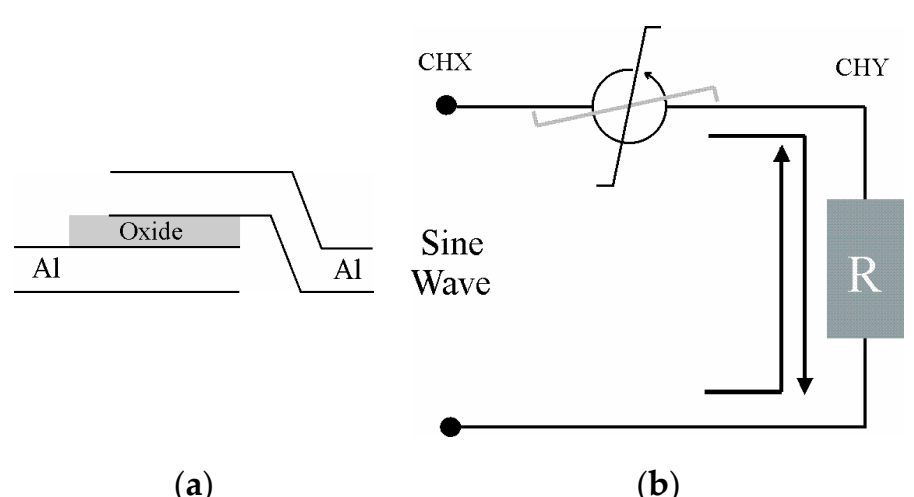

(a)

(b)

Figure 2. Aluminum oxide-based structure: (a) schematic diagram to demonstrate conduction phenomena;

(b) practical circuit used to measure the current-voltage plots.

The operation in aluminum oxide-based structure has been confirmed with the practical circuit of Figure $2 b$. To adjust the electrical current flow through this circuit when each samples was tested, graphite-based devices dependent on their distributed resistance and assembled on SiC sheets as substrates were used as resistors [18]. To assess practical-circuit performance; an empirical technique well known as a transfer function for the analysis of the linear systems in control theory, is used here to correlate the current-voltage characteristics and internal states of each sample, where a relationship describing the charge carriers conduction under operation understands the ratio of the output variable to the input variable [19].

To extract electrical signals from the practical circuit, a sine wave was connected in series with the scheme of Figure $2 \mathrm{a}$ and with $100 \Omega$ and $56 \Omega$ load resistors, respectively. The sine wave was measured directly as CHX input oscilloscope signal, and the equivalent electrical current flow was monitored 
by determining the voltage across of the load resistors as $\mathrm{CHY}$ input oscilloscope signal as shown in Figure $2 b$.

Figure 3a-c displays the current-voltage plots of each aluminum oxide-based structure tested with each one samples enlisted in Table 1 . As a reference, an electrical response of a recycled aluminum sheet connected in series with a $100 \Omega$ load resistor has been included as dotted line from Figure 3 a to Figure $3 c$ to emphasize that the electrical conduction is dependent on internal states proximate to the interface between each sample and electrode aluminum; hence, an electrical symbol for the aluminum oxide-based structure is also proposed in Figure $2 b$ to differentiate the internal states revealed in Figure 3. A phenomenological description related to the activation of each internal state is given below:

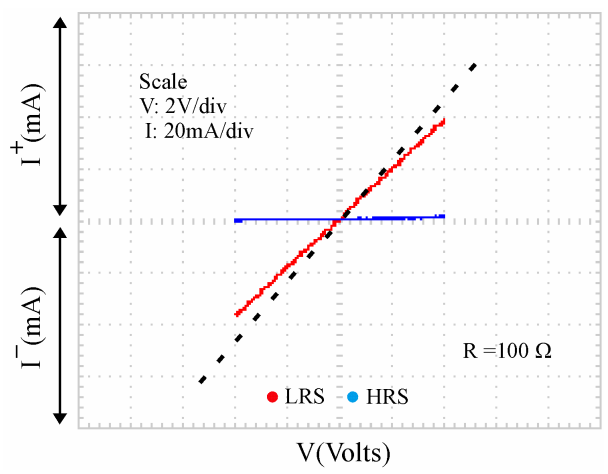

(a)

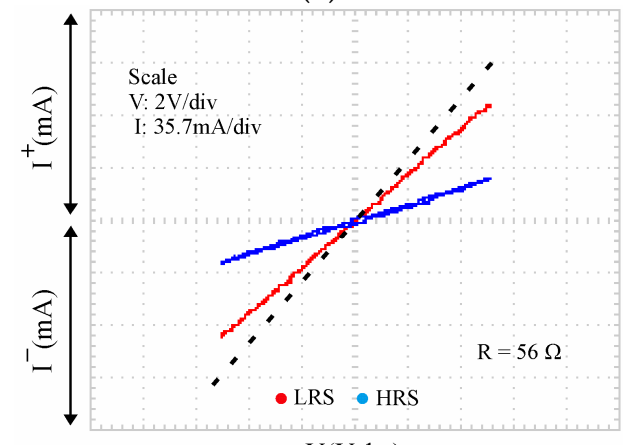

$\mathrm{V}$ (Volts)

(b)

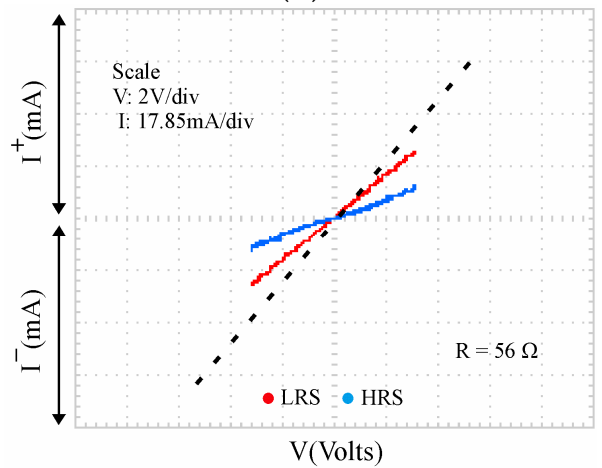

(c)

Figure 3. Current-voltage plots in aluminum oxide-based structures: (a) electrical conduction in sample AS-1; (b) electrical conduction in sample AS-2; and (c) electrical conduction in sample AS-3.

\subsection{High-Resistance State}

Because the aluminum ions are missing in the aluminum-oxide layer, it is disordered, which means that lattice defects occur. Therefore, the oxide must exhibit properties sensitive not only to stress states, but also to other variables including aluminum vacancies, variation in oxide composition, thickness, etc. 
In order to know how electrical conduction is caused by the electric field applied in the practical circuit, current-voltage plots help to reveal that the Ohmic conduction observed will be strongly depended on attractive electrostatic forces, $F_{a}$, where aluminum and oxygen ions are being well polarized as shown in Figure 4a, until the injected carriers from the aluminum electrodes can be collected by these vacancies, which act as trapping sites when temperature increases from the interface.

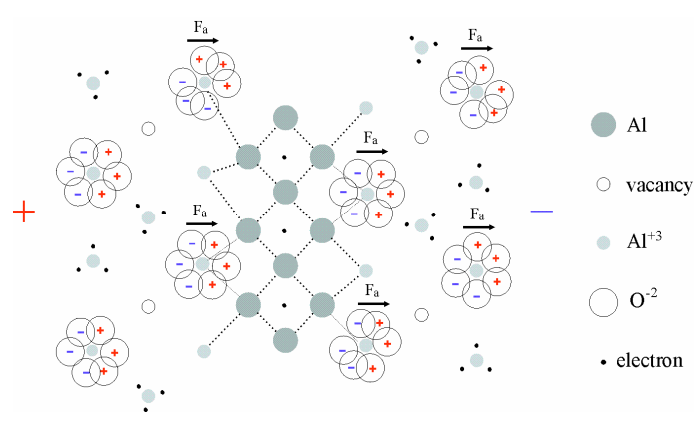

(a)

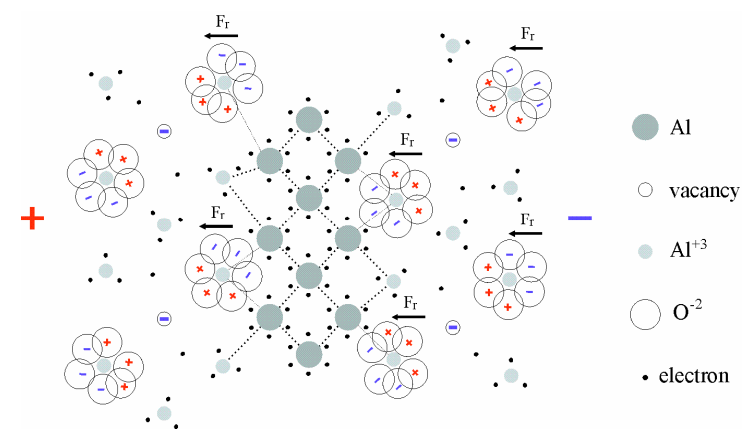

(b)

Figure 4. Schematic view to describe physical phenomena inside each sample: (a) at high-resistance state; (b) at low-resistance state. Figures show how many species can be influenced by electrostatic interactions and temperature.

\subsection{Low-Resistance State}

By increasing in the electric field and temperature through each aluminum-oxide layer in the practical circuit, the electrons trapped in aluminum vacancies are favored and as a consequence aluminum and oxygen ions will depolarize as a function of repulsive electrostatic forces, $\mathrm{F}_{\mathrm{r}}$, as shown in Figure $4 b$, causing the structure to change in resistance with moderate conduction being influenced by the capability of the trapping sites to be occupied.

The effect of increasing thermal activation will be also dependent on high energy of injected electrons, such that a constant conduction is maintained.

The physical description previously made discloses that both compressive (-) and tensile (+) states from X-ray diffraction and charge carries conduction from electrical conduction could be responsible for the change in resistance of each sample, where carrier activation energy between $2 \mathrm{eV}$ to $4 \mathrm{eV}$, in accordance to the measured voltage transition in current-voltage plots, assumes at what voltage magnitude a change in resistance could occur, whose magnitude will differ as a function of the synthesis process in each one of the aluminum-oxide layers, and it must take place when the electron density reaches a critical quantity triggered by an time-variant electrical current.

The resulting current-voltage plots were found to be rather peculiar; the operating properties such as $R_{\mathrm{OFF}} / \mathrm{R}_{\mathrm{ON}}$ ratio, switching speed, retention time, and endurance [20], being defined for switching-mode conduction, were estimated here from the current-voltage plots and collected in Table 2. These collected data only reflect the degree to which the aluminum oxide-based structures were tested. It should be noted that due to the activation energy were not sufficiently high to dielectric breakdown in the samples; therefore, in Figure 3a, it can be assumed that the oxide was enhanced with aluminum vacancies being equivalent to an aluminum-rich oxide layer, which resulted that $\mathrm{R}_{\mathrm{OFF}} / \mathrm{R}_{\mathrm{ON}}$ ratio was moderately high and the switching speed was lower, but retention and endurance were a short time. In contrast, Figure $3 b, c$ assumes that the oxide is poorer with a reduced number of aluminum vacancies whose composition is equivalent to an oxygen-rich oxide layer, which results in both retention and endurance being extended time $(>1 \mathrm{~h})$, switching speed above $100 \mu \mathrm{sec}$, and $\mathrm{R}_{\mathrm{OFF}} / \mathrm{R}_{\mathrm{ON}}$ ratio being lower. 
Table 2. Operating parameters expected for the aluminum oxide-based architectures useful as functional devices.

\begin{tabular}{ccccc}
\hline Sample & R $_{\text {OFF }} / \mathbf{R}_{\text {ON }}$ & Switching Speed & Retention Time & Endurance \\
\hline AS-1 & 30 & $20 \mu \mathrm{s}$ & $10^{3} \mathrm{~s}$ & $\sim 10^{2}$ \\
AS-2 & 2.5 & $500 \mu \mathrm{s}$ & $10^{5} \mathrm{~s}$ & $\sim 10^{4}$ \\
AS-3 & 2 & $1 \mathrm{~ms}$ & $10^{5} \mathrm{~s}$ & $\sim 10^{4}$ \\
\hline
\end{tabular}

\section{Opportunities for Application}

Nowadays, the electronic industry is inspired by circuit architectures operating from room temperature up to $40{ }^{\circ} \mathrm{C}$ under switching-mode conduction, whose complex building blocks are manufacturing by silicon-based CMOS technology [20,21]; therefore, although the effects of defective structure in metal oxides can be still unclear today, taking advantage of the disorder-influenced electrical properties in aluminum oxide-based structures could be crucial to operate these under feasible conditions during prolonged lifetime, where their time-variant switching phenomena is advantageously dependent on temperature and electrostatic interactions in contrast to the switching-mode conduction that is well-known in silicon-based semiconductor devices [21]. In this section, based on aluminum oxide response detailed in Section 3, some theoretic models for circuit architectures are discussed.

\subsection{Synthesis of Square-Wave Pulses}

To demonstrate that an aluminum oxide-based structure can provide a reasonable model for at least one type of waveform synthesis circuit, let us consider the circuit shown in Figure 5, where the timing signals to drive that circuit configuration are also included. The behavior in the switches $S_{1}$ and $\mathrm{S}_{2}$ will be equivalent to applying square-wave pulses, where the changes from low-resistance state (LRS) to high-resistance state (HRS), as a function of the voltage magnitude and rise and fall times in the switches $S_{1}$ and $S_{2}$, must be depend on the ON and OFF states. Additionally, a memory state can occur when both switches $S_{1}$ and $S_{2}$ retain equal state in a specified period of time.

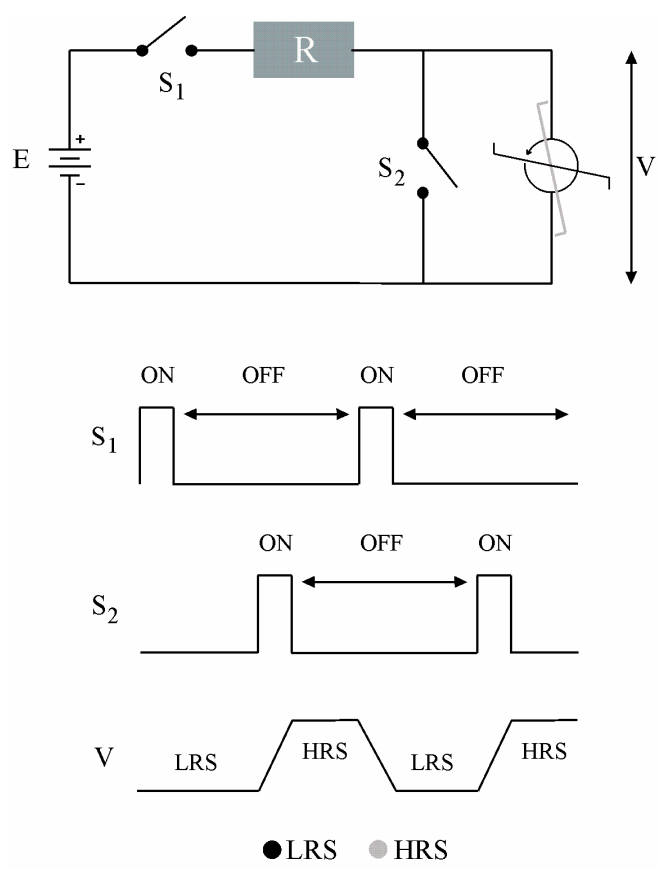

Figure 5. Timing circuit inspired on time-variant switching phenomena. The figure shows a theoretic circuit for synthesis of square-wave pulses and their performance. 
From the Figure 5, the output voltage $\mathrm{V}_{0}$ is almost identical to the corresponding waveform measured in a timing circuit [22]. The discrepancy between the waveform for a timing circuit and the waveform for the device synthesized in Figure 5 will be that always a time delay will occur to switch from a low to a high resistance and at opposing manner. Under this model, the time delay is dependent on aluminum kind, oxide composition, and dimensions (thickness and junction area), thus, for this example, an aluminum-rich oxide layer must be preferred.

\subsection{Analog-Digital Conversion}

Before, briefly must be understood the analog-digital conversion as a signal processing type, where analog switches can be sequenced by successive approximation logic enabled by clock cycles (square-wave pulses) to match analog input voltage to a corresponding tap on each resistor into an network of $\mathrm{N}$ resistors, being equivalent to a digital N-bit binary code. To complete any conversion, $M$ clock cycles must follow during each bit tested from the most significant bit (MSB) until the least significant bit (LSB). Finally, the digital N-bit binary code will be transferred to an output latch, where the code is retained and then an interruption will be asserted to give the conversion and reset all the analog switches to initiate a new conversion [23]. Because of the analog-digital conversion, numerous operations must be made by complex control sequences; instead, a simplifying conversion type could be modeled by an array of four waveform synthesis circuits connected as shown in Figure 6 .

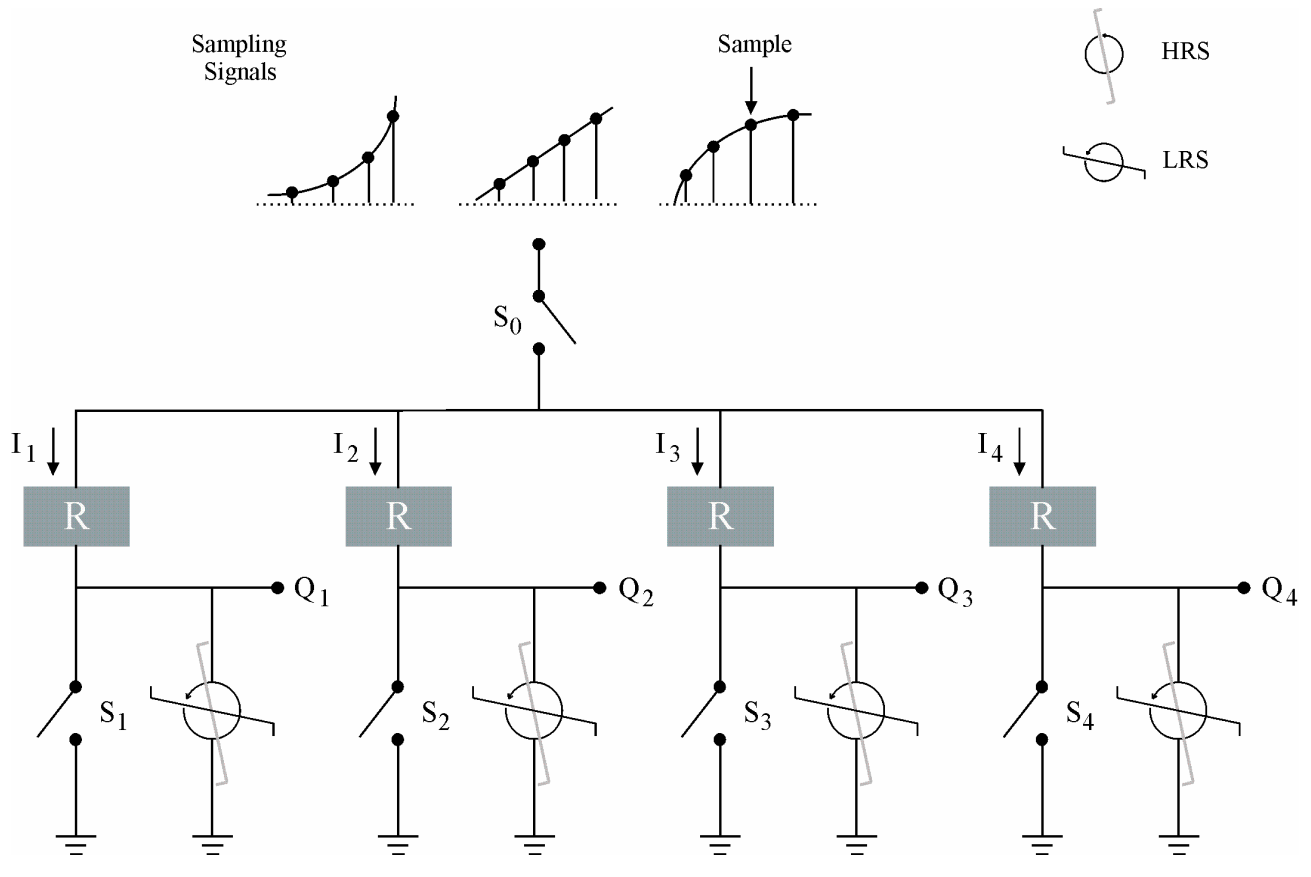

Figure 6. Analog-digital conversion inspired on theoretic array by four waveform synthesis circuits.

Figure show as the analog-digital conversion can be useful to optimized signal processing.

To understand this model, let us consider that each one of these circuits will consist of graphite-based resistors of growing resistor size $\left(R_{1}<R_{2}<R_{3}<R_{4}\right)$, four switches labeled as $\mathrm{S}_{1}, \mathrm{~S}_{2}, \mathrm{~S}_{3}$, and $\mathrm{S}_{4}$, which are equivalent to applying square-wave pulses with specified period of time, and four aluminum oxide-based structures. The resistor size depends on physical properties of the oxygen-rich oxide layers that are preferred to be used in the analog-digital conversion for the scheme of Figure 6. The scheme for analog-digital conversion suggested here is essentially a current divider, where each output $Q_{1}, Q_{2}, Q_{3}$, and $Q_{4}$ will be high-resistance state (HRS) or low-resistance state (LRS) when each switch labeled as $S_{1}, S_{2}, S_{3}$, and $S_{4}$ is open or closed. In accordance to Table 3 , the operating state when an analog-digital conversion performs under three cycles: (1) conversion; (2) erasing; and (3) storing is described in the following: 
Table 3. Operating states for the analog-digital conversion in Figure 6 modeled by aluminum oxide-based structures.

\begin{tabular}{|c|c|c|c|c|c|c|c|c|}
\hline $\begin{array}{l}\text { Operating } \\
\text { Cycle }\end{array}$ & $\mathrm{S}_{0}$ & $\mathrm{~S}_{1}$ & $\mathrm{~S}_{3}$ & $\mathrm{~S}_{4}$ & $\mathrm{Q}_{1}$ & $\mathrm{Q}_{2}$ & $\mathrm{Q}_{3}$ & $\mathrm{Q}_{4}$ \\
\hline \multirow{4}{*}{ Conversion } & \multirow{4}{*}{ Closes } & & \multirow{4}{*}{ All Open } & & LRS & HRS & HRS & HRS \\
\hline & & & & & LRS & LRS & HRS & HRS \\
\hline & & & & & LRS & LRS & LRS & HRS \\
\hline & & & & & LRS & LRS & LRS & LRS \\
\hline Erasing & Opens & & \multicolumn{2}{|l|}{ All Close } & HRS & HRS & HRS & HRS \\
\hline- & Closes & & \multicolumn{2}{|l|}{ All Open } & \multicolumn{4}{|c|}{ Conversion } \\
\hline Storing & Opens & & All Open & & LRS & LRS & HRS & HRS \\
\hline
\end{tabular}

At the conversion cycle, the switch $S_{0}$ closes and gradually each output $Q_{1}, Q_{2}, Q_{3}$, and $Q_{4}$ will change their state as a function of the voltage magnitude of each sample; hence, four electric current paths labeled as $\mathrm{I}_{1}, \mathrm{I}_{2}, \mathrm{I}_{3}$, and $\mathrm{I}_{4}$ allow each aluminum oxide-based structure to change its electrical conduction, as shown by the equivalent symbols indicated in Figure 6. Next, the binary code that matches the analog voltage will be represented by the state fixed in the outputs. At the erasing cycle, first, a conversion cycle must be completed, next, the switch $S_{0}$ opens and the switches from $S_{1}$ to $S_{4}$ close; therefore, each output $Q_{1}, Q_{2}, Q_{3}$, and $Q_{4}$ will change their electrical conduction, until new a condition in the switches from $\mathrm{S}_{0}$ to $\mathrm{S}_{4}$ occurs. At the storing cycle, first, a conversion cycle as a function of the voltage magnitude of interest must occur, which means that when the switch $\mathrm{S}_{0}$ opens, only the electrically switched outputs will remain in LRS during a prolonged time delay. Under this cycle, only each structure activated will change its internal state as shown in Table 3. All switches from $\mathrm{S}_{1}$ to $\mathrm{S}_{4}$ must be open during a storing cycle. The performance of these three operating cycles assume that the scheme in Figure 6 could be useful for a sensing application, where for example, physical, chemical and biological specimens could be activated by square signals or by sampling signals under detection-extended times [21,24].

\section{Conclusions}

Aluminum oxide-based structures are synthesizing by a corrosion/oxidation process from the recycled aluminum sheets. Studies of X-ray diffraction and electrical conduction have confirmed that the dynamic behavior of electron carriers trapped in vacancies is associated with a disordered array of aluminum and oxygen ions inside a crystalline lattice of aluminum oxide. To ensure a feasible solid-waste management system in the next few years; transforming beverage cans into a second life has been suggested in this work, where the interrelationship of green synthesis and time-variant switching phenomena has shown recycling benefits; these phenomena arising from a result of empirical methodologies for materials research. Furthermore, some circuit architectures have been theoretically detailed to demonstrate how disorder-influenced electrical conduction can provide routes to build functional devices from a sustainable point of view, where specific solutions using uncommon material qualities and variations of existing electronic modules based on mature CMOS technology, will lead to advances in emerging sustainable technologies dependent on optimized signal processing.

Author Contributions: R.B.-A. as author of this manuscript conceived the synthesis processes, analyzed the results, and wrote all the manuscript. Furthermore, the author planned the research topic and development. All authors have read and agreed to the published version of the manuscript.

Funding: This research received no external funding and the APC was funded by the author.

Acknowledgments: The research was supported in part by the National Council of the Science and Technology (CONACyT), Mexico. The structural data collected from XRD studies has been possible thanks to Norberto Hernández-Como from CNMN belonging at the National Polytechnic Institute, Mexico.

Conflicts of Interest: The author declares no conflict of interest. 


\section{References}

1. Ozerov, M.S.; Gazizova, M.Y.; Klimova, M.V.; Stepanov, N.D.; Zherebtsov, S.V. Effect of Plastic Deformation on the Structure and Properties of the Ti/TiB Composite Produced by Spark Plasma Sintering. Russ. Metall. 2018, 2018, 638-644. [CrossRef]

2. Bomberger, H.B.; Cambourelis, P.J.; Hutchinson, G.E. Corrosion Properties of Titanium in Marine Environments. J. Electrochem. Soc. 1954, 101, 442-447. [CrossRef]

3. U.S. Geological Survey. Mineral Commodity Summaries 2020: U.S. Geological Survey. 2020. Available online: https://doi.org/10.3133/mcs2020 (accessed on 1 July 2020).

4. Piero, D. Occurrence, exposure, effects, recommendation intake and possible dietary use of selected trace compounds (aluminum, bismuth, cobalt, gold, lithium, nickel, silver). Int. J. Food Sci. Nutr. 2014, 65, 911-924.

5. Cotton, A.; Wilkinson, G. Advanced Inorganic Chemistry, 4th ed.; John Wiley \& Sons: New York, NY, USA, 2008.

6. Brown, T.J.; Hetherington, L.E.; Hannis, S.D.; Bide, T.; Benham, A.J.; Idoine, N.E.; Lusty, P.A.J. World Mineral Production 2003-2007; British Geological Survey: Nottingham, UK, 2009; Available online: www.bgs.ac.uk (accessed on 1 June 2020).

7. Rosseland, B.O.; Eldhuset, T.D.; Staurnes, M. Environmental effects of aluminum. Environ. Geochem. Health 1990, 12, 17-27. [CrossRef] [PubMed]

8. Baca, R. Recovery of electronics waste to be converting into functional devices. MRS Adv. 2019, 4, 1067-1075. [CrossRef]

9. Nakashima, P.N.H. The Crystallography of Aluminum and Its Alloys. In Encyclopedia of Aluminum and Its Alloys, 1st ed.; Totten, G.E., Tiryakioglu, M., Kessler, O., Eds.; CRC Press: Boca Raton, FL, USA, 2018; pp. 488-586.

10. Belkin, A.; Bezryadin, A.; Hendren, L.; Hubler, A. Recovery of Alumina Nanocapacitors after High Voltage Breakdown. Sci. Rep. 2017, 7, 932. [CrossRef] [PubMed]

11. Jadhav, U.; Hocheng, H. Hydrometallurgical Recovery of Metals from Large Printed Circuit Board Pieces. Sci. Rep. 2015, 5, 14574. [CrossRef] [PubMed]

12. Fewster, P.F. X Ray Scattering from Semiconductors, 2nd ed.; Imperial College Press: London, UK, 2003.

13. Galasso, F.S. Structure and Properties of Inorganic Solids, 1st ed.; Pergamon Press Inc.: Oxford, UK, 1970.

14. Baik, S.J.; Lim, K.S. Bipolar resistance switching driven by tunnel barrier modulation in TiOx/AlOx bilayered structure. Appl. Phys. Lett. 2010, 97, 072109. [CrossRef]

15. Qi, Y.; Shen, Z.; Zhao, C.; Zhao, C.Z. Effect of electrode area on resistive switching behavior in translucent solution-processed AlOx based memory device. J. Alloys Comp. 2020, 822, 153603. [CrossRef]

16. Shima, H.; Zhong, N.; Akinaga, H. Switchable rectifier built with $\mathrm{Pt} / \mathrm{TiO} x / \mathrm{Pt}$ trilayer. Appl. Phys. Lett. 2009, 94, 082905. [CrossRef]

17. Omar Cooke, K. Introductory Chapter: Structural Aluminum Alloys and Composites. In Aluminum Alloys and Composites; Omar Cooke, K., Ed.; IntechOpen: London, UK, 2020; Available online: https: //www.intechopen.com/10.5772/intechopen.90569 (accessed on 10 August 2020).

18. Baca Arroyo, R. Graphite Intended for Green Engineering Developed by Noncontaminant Reverse Abrasion. Adv. Mater. Sci. Eng. 2016, 2016, 7016457. [CrossRef]

19. Khalil, H.K. Nonlinear Systems, 3rd ed.; Prentice Hall, Inc.: Upper Saddle River, NJ, USA, 2002.

20. Ha, S.D.; Ramanathan, S. Adaptive oxide electronics: A review. J. Appl. Phys. 2011, 110, 071101. [CrossRef]

21. Sze, M.S. Physics of Semiconductor Devices, 3rd ed.; John Wiley \& Sons, Inc.: New York, NY, USA, 2007; pp. 293-373, 743-771.

22. Sedra, A.S.; Smith, K.C. Microelectronics Circuits, 5th ed.; Oxford University Press: New York, NY, USA, 2004; pp. 1165-1229.

23. Manganaro, G. Advanced Data Converters, 1st ed.; Cambridge University Press: New York, NY, USA, 2012; pp. 42-120.

24. Zafar, S.; Lu, M.; Jagtiani, A. Comparison between Field Effect Transistors and Bipolar Junction Transistors as Transducers in Electrochemical Sensors. Sci. Rep. 2017, 7, 41430. [CrossRef] [PubMed]

(C) 2020 by the author. Licensee MDPI, Basel, Switzerland. This article is an open access article distributed under the terms and conditions of the Creative Commons Attribution (CC BY) license (http://creativecommons.org/licenses/by/4.0/). 